\title{
Estimation and Assessment of D-Dimer Levels in Sudanese Patients with Pulmonary Tuberculosis
}

\author{
Sahar Abdelhameed Abass Alhassan, Nasr Eldeen Ali Mohammed Gaufri* \\ Department of Hematology, Faculty of Medical Laboratory Sciences, Alneelain University, Khartoum, Sudan \\ Email: *Nasralimohammed@yahoo.com
}

How to cite this paper: Alhassan, S.A.A. and Gaufri, N.E.A.M. (2017) Estimation and Assessment of D-Dimer Levels in Sudanese Patients with Pulmonary Tuberculosis. Open Access Library Journal, 4: e3211. https://doi.org/10.4236/oalib.1103211

Received: December 29, 2016

Accepted: February 3, 2017

Published: February 6, 2017

Copyright $\odot 2017$ by authors and Open Access Library Inc.

This work is licensed under the Creative Commons Attribution International License (CC BY 4.0).

http://creativecommons.org/licenses/by/4.0/ (c) (i) Open Access

\begin{abstract}
Background: The association between pulmonary tuberculosis and a hypercoagulable state is well documented. An increased D-dimer level is linked with increasing the mortality of pulmonary tuberculosis infection. Objective: The current study aimed to the estimation and assessment of the D-dimer levels in Sudanese patients with pulmonary tuberculosis. Material and Methods: This is a case control study that was conducted during March 2016 at Faculty of Medical Laboratory Sciences, Alneelain University, Khartoum, Sudan. A total of 70 subjects were included in this study, classified into two groups. The first group consists of 40 subjects, among which 30 (75\%) were males and $10(25 \%)$ were female; their mean age is 32.3 years classified as patients group; of other 30 normal healthy subjects, 15 (50\%) were female and 15 (50\%) were males; their mean age was 33.1 years in the second group as normal control group. The platelet poor plasma was prepared immediately from citrated blood by centrifuging at $2000 \mathrm{rpm}$ for 15 minutes. The data were collected by structured interview and questionnaire, and then analyzed by using a computer program statistical package for social sciences (SPSS) version 21. The D-dimer levels were measured using immunometric assay (Nyco Card READER II). Result: The present study found that the D-dimer levels were statistically significantly higher in pulmonary tuberculosis patients compared to the normal healthy control groups (Mean \pm SD $0.82 \pm 0.54$ vs. $0.33 \pm 0.13$ with p value $0.00)$. Conclusion: This study showed that Sudanese patient with pulmonary tuberculosis has increased the plasma D-dimer level, and this abnormality could be prone to Deep Vein Thrombosis (DVT).
\end{abstract}

\section{Subject Areas}

Hematology 


\section{Keywords}

D-Dimer, Mycobacterium tuberculosis, TB, Sudan

\section{Introduction}

Tuberculosis, MTB, or TB (short for tubercle bacillus), is a widespread infectious disease caused by various strains of mycobacterium, usually Mycobacterium tuberculosis [1]. Tuberculosis typically attacks the lungs, but can also affect other parts of the body. It is spread through the air when people who have an active TB infection cough, sneeze, or otherwise transmit respiratory fluids through the air [2]. Pulmonary tuberculosis (PTB) is a lower respiratory tract infection that is initiated by the deposition of Mycobacterium tuberculosis (MTB) contained in aerosol droplets, onto lung alveolar surfaces. The active disease is characterized by protracted cough, fatigue, loss of weight and appetite and night sweats. Hemoptysis, secondary infection by fungi and permanent lung damage are few of the complications of PT [3]. Tuberculosis is the second-most common cause of death from infectious disease (after those due to HIV/AIDS) [4]. The total number of tuberculosis cases has been decreasing since 2005, while new cases have decreased since 2002 [5]. China has achieved particularly dramatic progress, with about an $80 \%$ reduction in its TB mortality rate between 1990 and 2010 [6]. The number of new cases has declined by 17\% between 2004-2014 [7]. Tuberculosis is more common in developing countries; about $80 \%$ of the population in many Asian and African countries tests positive in tuberculin tests, while only $5 \%-10 \%$ of the US population tests positive [1]. Thromboembolic complications associated with infection by pulmonary tuberculosis have been reported in the literature that occurred in $1.5 \%-3.4 \%$ of TB infection, which is a risk factor for Deep Vein Thrombosis (DVT) related to hypercoagulable state secondary to inflammatory state [8]. What can be diagnosed by D-dimer test is a Fibrin Degradation Product (FDP), a small protein fragment present in the blood after a blood clot is degraded by fibrinolysis. It is so named because it contains two cross linked D fragments of the fibrin protein [9]. It is postulated that association between inflammation and hemostatic changes arising in pulmonary tuberculosis can result in hypercoagulable state which may predispose to DVT. The interaction between mycobacterial products and the monocyte macrophage system synthesizes large amounts of TNF- $\alpha$ and interleukin-6, which changes the normally non-thrombogenic internal surface of the vessel into a thrombogenic surface that may lead to development of local thrombosis [10]. Coagulation system plays an important role in pleural diseases, and to make an understanding of pathophysiological mechanisms between coagulation and pleural disorders may open possibilities for novel diagnostic and therapeutic approaches [6]. Several studies have reported that TPE is associated with enhanced local fibrinolytic activity. Thus, D-dimer level, a marker of solid phase fibrin dissolution was found to be high in patients with TPE [7] [11]. This study 
aimed to the estimation and assessment of the plasma D-dimer levels in Sudanese patients with pulmonary tuberculosis.

\section{Materials and Methods}

This is analytical descriptive case control conducted in Al-Neelain University Faculty of Medical Laboratory Sciences, Khartoum, Sudan and Aboanja teaching hospital, Omdurman, Sudan during March 2016. A total of 70 subjects were enrolled in this study, designated in two groups, the first consist of 40 subjects, $30(75 \%)$ were males and $10(25 \%)$ were female; their mean age is 32.3 years as patients group known diagnosed by TB; 21 (52.55) were in chronic phase while 19 (47.55) in acute phase of the disease. Further 30 normal healthy subject 15 (50\%) were female and 15 (50\%) were males; their mean age was 33.1 years, designated as normal control group. This study was approved by Aboanja hospital teaching hospital and Al Neelain University ethical committee. The informed consent also obtained from all participants before sample were collection. Under full aseptic condition veins sample were collected in trisodium citrate container, then platelet-poor plasma was prepared (PPP) by centrifugation at $2000 \mathrm{~g}$ for 15 min at $4 \mathrm{c}$. The D-dimer level was measured by immunometric assay (Nyco Card READER II)-USA. Patients excluded from this study if they have a history of haemostatic abnormalities, malignancy, trauma, patients under anticoagulant thereby, alcoholism, and liver disorder or with other inflammation disorders. The data was analyzed by using a computer program statistical package for social sciences (SPSS) version 21.

T. test were used from comparison between different study groups, the level of statistical significance was set at less than 0.05 .

\section{Results}

The analysis of this study revealed that the plasma D-dimer levels were statistically significant higher in pulmonary tuberculosis patients compared to the normal healthy control groups (Mean \pm SD $0.82 \pm 0.54$ vs. $0.33 \pm 0.13$ with $p$ value 0.00 ) (Table 1).

According to onset of the disease this study showed that the patients in acute phase have statistically significant higher D-dimer levels compared with patients in chronic pulmonary tuberculosis with p value 0.02 (Table 2 ).

Based on the gender this study showed there is no any statistically significant difference between the patients male and female (Table 3 ).

Table 1. Correlation of plasma D-dimer level in patient and normal control group.

\begin{tabular}{cccccc}
\hline \multirow{2}{*}{ parameter } & Type & Number & Mean & Std. Deviation & P value \\
\hline \multirow{2}{*}{ D-dimer } & patients & 40 & 0.82 & 0.54 & 0.00 \\
& Control & 30 & 0.33 & 0.13 & \\
\hline
\end{tabular}


Table 2. Correlation of plasma D-dimer levels in patient with TB according to onset of the disease.

\begin{tabular}{cccccc}
\hline parameter & Status & Number & Mean & Std. Deviation & P value \\
\hline \multirow{2}{*}{ D-dimer } & Chronic & 21 & 0.72 & 0.54 & 0.02 \\
& Acute & 19 & 0.91 & 0.52 & \\
\hline
\end{tabular}

Table 3. Correlation of plasma D-dimer levels in patient according their Gender.

\begin{tabular}{cccccc}
\hline parameter & Sex & $\mathrm{N}$ & Mean & Std. Deviation & P value \\
\hline \multirow{2}{*}{ D-dimer } & Male & 30 & 0.76 & 0.52 & 0.23 \\
& Female & 10 & 0.99 & 0.55 & \\
\hline
\end{tabular}

\section{Discussion}

Sudan is a large country with a diverse population and history of civil conflict. Poverty levels are high with a gross national income per capita of less than two thousand dollars. The country has a high burden of tuberculosis (TB) with an estimated 50,000 incident cases during 2009, when the estimated prevalence was 209 cases per 100,000 of the population [7] [12]. Actually, tuberculosis is a disease with a wide variety of clinical presentations and recently, the association between inflammation, hemostatic changes and a hypercoagulable state has been established [13] [14]. Robson et al. suggested that elevated plasma fibrinogen, impaired fibrinolysis coupled with decreased levels of antithrombin III and reactive thrombocytosis appeared to favor the development of DVT in pulmonary TB [12] [13]. Other researcher also mentioned that pulmonary TB has several mechanisms that can induce a hypercoagulable state which may lead to thromboembolic complications. Various studies have concluded that the high level of plasma fibrinogen, impaired fibrinolysis associated with a decrease in antithrombin III, protein C and platelet aggregation appear to induce a hypercoagulable state promoting the development of deep vein thrombosis pulmonary tuberculosis [5] [13] [15]. The current study was aimed to measure and assessment the plasma D-dimer levels in Sudanese patients with pulmonary tuberculosis. The present study showed that the plasma D-dimer levels were statistically significant higher in pulmonary tuberculosis patients compared to those normal healthy control groups (Mean \pm SD $0.82 \pm 0.54$ vs. $0.33 \pm 0.13$ with p value 0.00 ). This finding was in agreement with several previous studies, the first is that done by Ekrem Cengiz Seyhan, in Turkey who demonstrates in case study 22 patients with pulmonary tuberculosis and reported the D-dimer was higher in patient group [14]. The second study reported by Chinese authors Y. SHEN, T et al. in 2013 and concluded that the D-dimer levels was significant high in patient group [15]. The third study cited by Indian authors Dheeraj Gupta et al. in 2004 and they found that $\mathrm{D}$-dimers were positive in $30 \%$ patients [16]. The fourth study is similar with our findings that reported by Turkey authors Güliz Ataç et al. [17]. The sixth study was done in Bangladesh (2015) by Kager LM et al. who concluded that there is a significant higher in $\mathrm{D}$-dimer in patient than normal con- 
trol [18]. Our finding in the same line with the studies mentioned above .Based on the gender the current study showed that there is no statistically significant difference between the patients male and female with pulmonary tuberculosis and D-dimer levels. The present study found an association between inflammation and hemostatic changes that can result in an acute phase response and a hypercoagulable state. This finding is in agreement with the study done in 2015 by Kager LM et al. [18].

The main limitations in our study are the small sample size, and relatively short study period.

\section{Conclusion}

This study has shown that pulmonary tuberculosis leads to the increase of D-dimer level in Sudanese patients. This may be contributing to the progress of local venous thromboembolism, so these patients should be screened for hemostatic defects to avoid Deep Vein Thrombosis (DVT) tendency.

\section{References}

[1] Ryan, K.J. and Ray, C.G. (2004) "Mycobacteria”. Sherris Medical Microbiology: An Introduction to Infectious Diseases. 4th Edition, McGraw-Hill, New York, 439.

[2] Bregani, E.R., Valcarenghi, C., Van Tien, T. and Monzani, V. (2013) Suggestive Criteria for Pulmonary Tuberculosis in Developing Countries. International Journal of Mycobacteriology, 2, 211-213.

[3] Fraser, R.S. (1992) Pulmonary Aspergillosis: Pathologic and Pathogenetic Features. Patholoannual, 28, 231-277.

[4] Malani, P.N. (2010) Mandell, Douglas, and Bennett's Principles and Practice of Infectious Diseases. JAMA, 304, 2067-2071. https://doi.org/10.1001/jama.2010.1643

[5] Organization, W.H. (2011) Global Tuberculosis Control: WHO Report 2010. World Health Organization.

[6] Organization, W.H. (2010) Global Tuberculosis Control: WHO Report 2010. World Health Organization.

[7] Kielstra, P. (2014) Ancient Enemy, Modern Imperative. A Time for Greater Action against Tuberculosis. The Economist.

[8] El Fekih, L., Oueslati, I., Hassene, H., Fenniche, S., Belhabib, D. and Megdiche, M.L. (2009) Association Thromboses Veineuses Profondes avec Tuberculose Pulmonaire. Tunis Med, 87, 328-329.

[9] Adam, S.S., Key, N.S. and Greenberg, C.S. (2009) D-Dimer Antigen: Current Concepts and Future Prospects. Blood, 113, 2878-2887. https://doi.org/10.1182/blood-2008-06-165845

[10] Petersen, K. (2010) Mandell, Douglas, and Bennett's Principles and Practice of Infectious Diseases. In: Mandell, G.L., Bennett, J.E. and Dolin, R., Eds., Vol. 51, Churchill Livingstone Elsevier, Philadelphia, 636-637.

[11] Philip-Joet, F., Alessi, M.C., Philip-Joet, C., Aillaud, M., Barriere, J.R., Arnaud, A. and Juhan-Vague, I. (1995) Fibrinolytic and Inflammatory Processes in Pleural Effusions. European Respiratory Journal, 8, 1352-1356.

[12] Eldin, G.S.S., Fadl-Elmula, I., Ali, M.S., Ali, A.B., Salih, A.L.G., Mallard, K., Bottomley, C. and Mcnerney, R. (2011) Tuberculosis in Sudan: A Study of Mycobacte- 
rium tuberculosis Strain Genotype and Susceptibility to Anti-Tuberculosis Drugs. BMC Infectious Diseases, 11, 1.

[13] Robson, S.C., White, N.W., Aronson, I., Woollgar, R., Goodman, H. and Jacobs, P. (1996) Acute-Phase Response and the Hypercoagulable State in Pulmonary Tuberculosis. British Journal of Haematology, 93, 943-949. https://doi.org/10.1046/j.1365-2141.1996.d01-1722.x

[14] Shen, Y., Yang, T., Jia, L., Wang, T., Chen, L., Wan, C., Wang, L., Yan, Y. and Yi, Q. (2013) A Potential Role for D-Dimer in the Diagnosis of Tuberculous Pleural Effusion. Age, 52, 15.

[15] Zahn, D.W. and Peirce, C.T. (1948) Venous Thrombosis and Pulmonary Embolism in Tuberculosis. The American Journal of Medicine, 5, 716-728. https://doi.org/10.1016/0002-9343(48)90149-1

[16] Gupta, D., Gupta, S., Balamugesh, T., Aggarwal, A.N. and Das, R. (2005) Circulating D-Dimers as a Marker of Disease Activity in Pulmonary Sarcoidosis. Indian Journal of Chest Diseases and Allied Sciences, 47, 175.

[17] Christ-Crain, M., Morgenthaler, N.G., Stolz, D., Müller, C., Bingisser, R., Harbarth, S., Tamm, M., Struck, J., Bergmann, A. and Müller, B. (2006) Pro-Adrenomedullin to Predict Severity and Outcome in Community-Acquired Pneumonia. Critical Care, 10, R96.

[18] Kager, L.M., Blok, D.C., Lede, I.O., Rahman, W., Afroz, R., Bresser, P., Van der Zee, J. S., Ghose, A., Visser, C.E. and De Jong, M.D. (2015) Pulmonary Tuberculosis Induces a Systemic Hypercoagulable State. Journal of Infection, 70, 324-334. https://doi.org/10.1016/j.jinf.2014.10.006

Submit or recommend next manuscript to OALib Journal and we will provide best service for you:

- Publication frequency: Monthly

- 9 subject areas of science, technology and medicine

- Fair and rigorous peer-review system

- Fast publication process

- Article promotion in various social networking sites (LinkedIn, Facebook, Twitter, etc.)

- Maximum dissemination of your research work

Submit Your Paper Online: Click Here to Submit

Or Contact service@oalib.com 